\title{
“NEWS ON AIR!” - AIR SURVEILLANCE REPORT FROM INTENSIVE CARE UNITS OF A TERTIARY CARE HOSPITAL
}

\author{
BARNINI BANERJEE ${ }^{1}$, CHIRANJAY MUKHOPADHYAY ${ }^{1 *}$, VANDANA KE ${ }^{1}$ \\ ARCHANA BUPENDRA ${ }^{1}$, MURALIDHAR VARMA ${ }^{2}$
}

${ }^{1}$ Department of Microbiology, Kasturba Medical College, Manipal, Karnataka, India. ${ }^{2}$ Department of Medicine, Kasturba Medical College, Manipal, Karnataka, India. Email: chiranjay@gmail.com

Received: 24 August 2016, Revised and Accepted: 08 September 2016

ABSTRACT

Background: The role of airborne microorganisms in the nosocomial infections is debatable since past. Very limited and inconclusive data available about the contribution of the air microflora, especially the multidrug resistant (MDR) one, to the hospital-acquired infections in the Intensive Care Units (ICUs).

Objective: To analyze the microbial population and their antimicrobial susceptibility pattern of the indoor air in relation to the nosocomial infections in the different ICUs at different periods in the tertiary care hospital.

Methods: Microbial monitoring of the air was performed in 5 different ICUs for 1 year by passive sampling method.

Results: A total of 221 air samples were collected for 1 year from five different ICUs. 92.53\% were Gram-positive bacteria and 8.11\% were Gramnegative bacteria. Staphylococcus spp. (34.21\%) and Acinetobacter spp. (63.04\%) were the most common isolated bacteria among Gram-positive and Gram-negative organisms, respectively, and among the fungal isolates, all of them were Aspergillus spp. (5.84\%) from the air sample. Ventilatorassociated pneumonia was the most common nosocomial infection and Acinetobacter spp. was the frequently isolated MDR organism.

Conclusion: Air could be the major source of nosocomial infections by MDR Gram-negative organisms in the ICUs which require special attention and surveillance.

Keywords: Air sampling, Intensive Care Units, Multidrug-resistant organisms, Nosocomial infection.

(C) 2016 The Authors. Published by Innovare Academic Sciences Pvt Ltd. This is an open access article under the CC BY license (http://creativecommons. org/licenses/by/4. 0/) DOI: http://dx.doi.org/10.22159/ajpcr.2016.v9s3.14867

\section{INTRODUCTION}

Contribution of airborne microorganisms in nosocomial infection is controversial since past. Most of the studies in developing and developed world mentioned about level and profile of microbial air contamination and the factors such as overcrowding, improper ventilation, increased movement, climatic conditions of tropical area such as high temperature, excess humidity, and moisture which facilitate the survival and colonization of microorganisms in the indoor air [1-4]. However, none of the studies were conclusive about the role of air microflora in nosocomial infection in the Intensive Care Unit (ICUs) especially if it is multidrug resistant (MDR). So far, very few studies had been done in the ICU environment such as Ríos-Yuil et al. [5] mentioned about the presence of various nosocomially significant fungus in the ICU of a general hospital and Huang et al. [6] tried to find out the potential correlation between airborne and surface contamination in two ICUs of Taiwan, and whether patient infections were related to microbial contamination in the ICU. Based on the limited background knowledge about microbial contamination of the ICU environment and their contribution to nosocomial infection in the ICU, the main objectives of this study were microbiological characterization of the air samples in relation to the nosocomial infections in the different ICUs at different periods in our tertiary care hospital.

\section{METHODS}

Microbial monitoring of the air was performed in 5 conventionally ventilated ICUs of 2032 bedded tertiary care hospital for 1 year. Air samples were taken in medicine ICU (MICU), general ICU (ICU2), neonatal ICU (NICU), pediatric ICU (PICU), and cardiothoracic ICU (CTI) at three consecutive times, with a 3-4 months interval between each sampling. In all theaters, air was supplied by a ventilation system designed to provide 15 air changes/hours (hr.) Settle plate method was adopted using blood agar plates. All the plates were exposed for $2 \mathrm{hrs}$. After overnight incubation at $37^{\circ} \mathrm{C}$, number of discrete colonies were counted for each sample. Separate colony counts were tabulated for molds and bacteria. Total number of colony forming units (cfu) were enumerated, and bio-load was calculated using following formula:

$\mathrm{B}=1000 \mathrm{~N} / \mathrm{RT} \mathrm{bcp} / \mathrm{m}^{3}$ (N=number of colonies counted on settle plate; $\mathrm{T}=$ duration of the test in minutes; $\mathrm{R}=$ air sampling rate in liters/minutes) [7]. The isolated bacterial colonies were identified by matrix-assisted laser desorption ionization time-of-flight VITEK ${ }^{\circledR}$ MS, and antimicrobial susceptibility testing for the isolates were done by VITEK ${ }^{\circledR} 2$ system (bioMérieux, Inc., Durham, NC). For the fungal colonies, Lactophenol cotton blue mount was done for genus level identification.

Definition: MDR organisms (MDROs) are defined as microorganisms, predominantly bacteria, those are non-susceptible to $\geq 1$ agent in $\geq 3$ antimicrobial categories [8].

\section{Statistical analysis}

All the variables were analyzed by Pearson's Chi-square test by IBM SPSS Statistics version 20.

\section{RESULTS}

Microbiological quality of the indoor air

A total of 221 (MICU=27, ICU2=57, PICU=37, NICU=64, CTI=36) samples were collected for 1 year from five different ICUs. Bacteria were present in all the air samples, whereas fungal growths were observed in (36/221) $16.3 \%$ of the samples. The descriptive data of bio-load and $\mathrm{cfu} / \mathrm{plate}$ obtained in all the ICUs are shown in Table 1. 
High bio-load observed in the MICU throughout the year. Mean bioload was higher in rainy season compare to summer or winter in all the ICUs, and the percentage of hospital-acquired infections increased and decreased proportionately with the bio-load in different ICUs (Fig. 1) However, neither significant $(\mathrm{p}=-0.082)$ seasonal variation of bio-load observed in different ICUs nor significant association found ( $p=-0.061)$ between bio-load and healthcare-associated infections (HAIs).

\section{Microbiological characterization of the air samples in relation to} the nosocomial infections

A total of 616 bacterial isolates obtained. 91.9\% (566/616) were Grampositive and $8.12 \%(50 / 616)$ were Gram-negativebacteria.Staphylococcus spp. $(195 / 570=34.21 \%)$ and Acinetobacter spp. $(29 / 50=58 \%)$ were the most common Gram-positive and Gram-negative organisms, respectively. Different Staphylococcus spp. isolated were Staphylococcus aureus, Staphylococcus hominis, Staphylococcus epidermidis, and Staphylococcus haemolyticus. None of the Staphylococcus spp. were drug resistant. Acinetobacter baumannii complex and Acinetobacter lowfii were the two species of Acinetobacter found in the air. Even Acinetobacter baumannii complex was frequently isolated pathogen from nosocomial infections in our ICUs followed by Pseudomonas aeruginosa. Among the fungal isolates, all of them were Aspergillus spp. in the air sample and were also isolated from two nosocomially infected patients. Microorganisms isolated from the air samples and from different nosocomial infections in the ICUs are shown in Fig 2. and Table 2. respectively.

Among the isolated Gram-negative bacilli (GNB), 40\% (20/46) were MDR pathogens. A. baumannii complex was most common MDRO $(12 / 20=60 \%)$ isolated from the air samples followed by $P$. aeruginosa (5/20) 25\%. Remaining 5\% includes MDR E.coli and Enterobacter cloacae. Even, all the Acinetobacter spp. and $70 \%$ of P. aeruginosa isolated from nosocomial infections in the ICUs were MDR strain. Different Gram-negative organisms isolated from the air samples and HAIs are shown in Fig. 3. Where among the Gram-positive organisms, methicillin-resistant $S$. aureus (MRSA) isolated from nosocomially infected patients but not from the air samples.

\section{DISCUSSION}

We report an observational study to test the hypothesis that the air could harbor microorganisms of potential nosocomial significance. Our

Table 1: Total air microbial load assessed by passive sampling (cfu/plate and bio-load) in ICUs

\begin{tabular}{|c|c|c|}
\hline Parameters & Cfu/Plate & Bio-load (bcp/m $\left./ \mathrm{m}^{3}\right)$ \\
\hline Mean & 28.9 & 19.4 \\
\hline SD & 29.2 & 17 \\
\hline Minimum & 1 & 1 \\
\hline $25^{\text {th }}$ percentile & 9 & 7 \\
\hline Median & 28 & 14 \\
\hline $75^{\text {th }}$ percentile & 36 & 27 \\
\hline Maximum & 172 & 102 \\
\hline
\end{tabular}

SD: Standard deviation, ICU: Intensive Care Unit

Table 2: Pathogens identified from different HAIs in the ICUs

\begin{tabular}{llllll}
\hline Organisms (Number) & VAP & SSI & UTI & BSI & Total \\
\hline A. baumannii complex & 17 & - & - & 1 & 18 \\
P. aeruginosa & 13 & 4 & - & - & 17 \\
K.pneumoniae & 11 & 4 & 2 & 6 & 23 \\
E. coli & 5 & 1 & 3 & - & 09 \\
Others* & 5 & 3 & 3 & 5 & 16 \\
Total & 51 & 12 & 8 & 12 & 83 \\
\hline
\end{tabular}

*Others: Methicillin-sensitive S. aureus (1 BSI, $1 \mathrm{SSI}$ ), Methicillin resistant Staphylococcus aureus (1BSI, 2 SSI, 2 VAP), Enterobacter cloacae (1 VAP, 2 UTI), Aspergillus spp. (2 VAP), Candida spp. (2 BSI), Citrobacter freundii (1 UTI). VAP: Ventilator-associated pneumonia, SSI: Surgical site infection, UTI: Urinary tract infection, BSI: Blood stream infection study observed maximum bio-load during the rainy season in different ICUs in contrast to Park et al. [9], due to the location of our hospital in tropical area where extreme monsoon persists for 5-6 months in a year with the high amount of moisture and humidity in the air responsible for generation of more bio-aerosols.

Similar to us, several studies demonstrated the presence of more Grampositive organisms than Gram-negative in the air of the ICUs [10]. Most frequent, Gram-positive organism isolated was Coagulase-negative Staphylococcus spp. (34\%) similar to the observation reported by Sudharsanam et al. in their study conducted in southern part of India [2]. However, in contrast to most of the other studies, our Gramnegative isolates from the air were MDR, which is a rare finding [11]. Acinetobacter spp. and Pseudomonas spp were also commonly isolated MDR GNBs in the ICUs [12]. They are also commonly isolated organisms

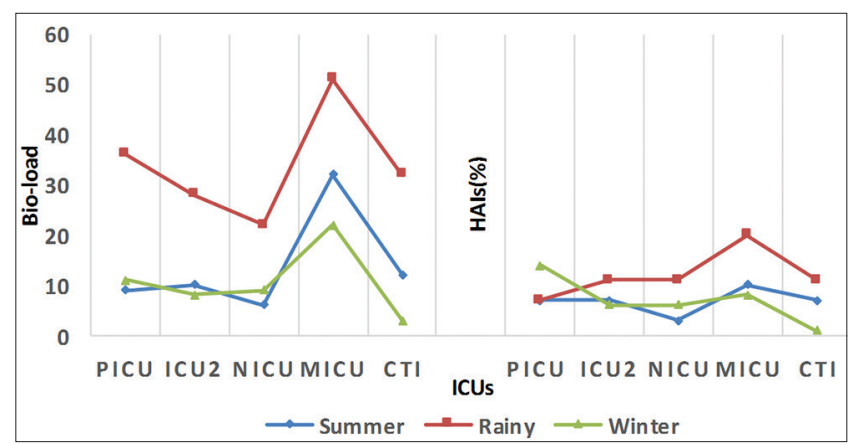

Fig. 1: Correlation between microbial air contamination and healthcare-associated infections in the five Intensive Care Units during three different seasons

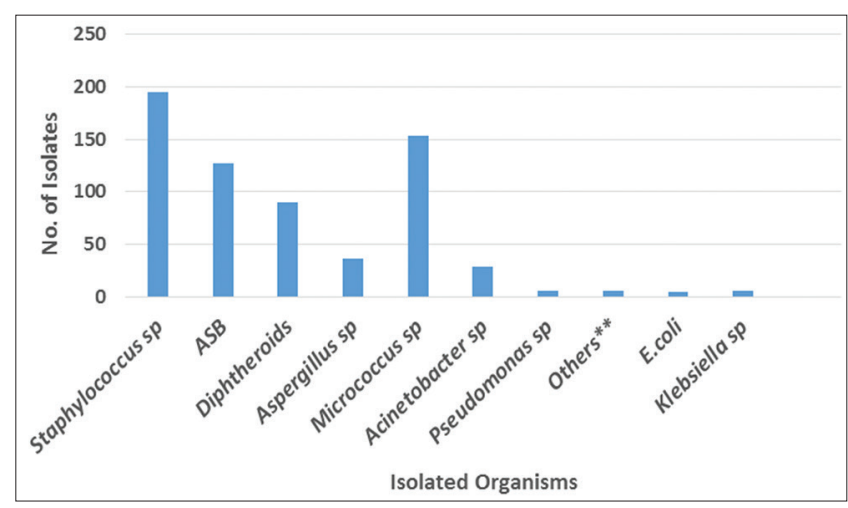

Fig. 2: Microorganisms in the air samples of different Intensive Care Units. **Others - Enterobacter sp., Citrobacter sp., and Proteus sp.

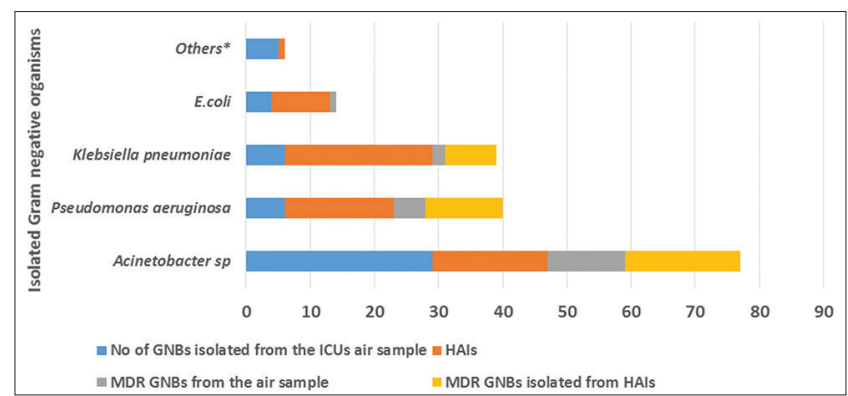

Fig. 3: Gram-negative organisms isolated from the air samples of different Intensive Care Units and healthcare-associated infections. *Others - Enterobacter sp., Citrobacter sp., and Proteus sp. 
from different nosocomial infections in our ICUs and probably air could be one of the sources. Colonization of the ICU air with ,Acinetobacter spp and Pseudomonas spp leads to nosocomial infections such as ventilatorassociated pneumonia and surgical site infections in critical patients reported by many studies [13-15]. Probably from the air they settle out on the inanimate objects, hands and the clothes of the healthcare workers and even the open wounds at the time of surgery. We also found the same. Their presence indicates, improper control of temperature and humidity of the ICU, high condensation due to excessive rainfall in addition to poor hand hygiene practice of the health-care personnel. Generation of aerosols from contaminated respiratory therapy equipment or during any other procedures in the ICUs like spirometry may also contribute their presence in the air. Absence of drug-resistant Gram-positive organisms in the air indicates, economically feasible screening protocol especially for the MRSA, may be required near future for all the health-care workers and the newly admitted patients who could be the probable source of these organisms in the ICUs.

The presence of Aspergillus spp. in the air of the ICU is worrisome as patients in the ICUs are usually severely ill or immunosuppressed prone to develop invasive fungal diseases [5]. Air conditioning system or the renovated ICUs are the common sources for them.

\section{CONCLUSION}

Air could be the major source of nosocomial infections by MDR Gramnegative organisms in the ICUs which is an alert for the healthcare workers and require special attention and surveillance. Along with the environmental factors, patient and health-care workers have equal contribution in bio-load variation and cross-transmission of infection in the ICUs. Improvement of ventilation system, environmental conditions, restricted human movement, strict barrier precaution, and installation of high-efficiency particulate arrestance filters will help in decreasing the infection rate in the ICUs. Guidelines for the patient to health-care workers ratio have to be generated and to be strictly maintained.

We need to do further study to know whether isolated air microbial population were real pathogen related to patient's infection and what are the other inanimate sources of HAIs in our ICUs.

\section{ACKNOWLEDGMENTS}

I would like to thank the Hospital Infection Control Committee of the Kasturba Hospital, Manipal, for providing the data related to this study.

\section{REFERENCES}

1. Abdollahi A, Mahmoudzadeh S. Microbiological profile of air contamination in hospital wards. Iran J Pathol 2012;7(3):177-82.

2. Sudharsanam S, Swaminathan S, Ramalingam A, Thangavel G, Annamalai R, Steinberg R, et al. Characterization of indoor bioaerosols from a hospital ward in a tropical setting. Afr Health Sci 2012;12(2):217-25.

3. Mahieu LM, De Dooy JJ, Van Laer FA, Jansens H, Leven MM. A prospective study on factors influencing Aspergillus spore load in the air during renovation works in a neonatal intensive care unit. J Hosp Infect 2000;45(3):191-7.

4. Scaltriti S, Cencetti S, Rovesti S, Marchesi I, Bargellini A, Borella P. Risk factors for particulate and microbial contamination of air in operating theatres. J Hosp Infect 2007;66(4):320-6.

5. Ríos-Yuil JM, Arenas R, Fernández R, Calderón-Ezquerro M, Rodriguez-Badillo R. Aeromycological study at the intensive care unit of the "Dr. Manuel Gea Gonzalez" general hospital. Braz J Infect Dis 2012;16(5):432-5.

6. Huang PY, Shi ZY, Chen CH, Den W, Huang HM, Tsai JJ. Airborne and surface-bound microbial contamination in two intensive care units of a medical center in central Taiwan. Aerosol Air Qual Res 2013;13:1060-9.

7. Collee JG, Fraser AG, Marmion BP, Simmons A. Mackie \& McCartney Practical Medical Microbiology. $14^{\text {th }}$ ed. New York: Churchill Livingstone, Elsevier; 2008.

8. Magiorakos AP, Srinivasan A, Carey RB, Carmeli Y, Falagas ME, Giske $\mathrm{CG}$, et al. Multidrug-resistant, extensively drug-resistant and pandrugresistant bacteria: An international expert proposal for interim standard definitions for acquired resistance. Clin Microbiol Infec 2012;18(3):268-81.

9. Park DU, Yeom JK, Lee WJ, Lee KM. Assessment of the levels of airborne bacteria, Gram-negative bacteria, and fungi in hospital lobbies. Int J Environ Res Public Health 2013;10:541-55.

10. Vackova MM, Hanovcova I, Smetana J, Chlibek R, Bostikova V, Splino M. Air load at the transplant intensive care unit. Mil Med Sci Lett (Vojen Zdrav Listy) 2011;80:52-7.

11. Lemmen SW, Häfner H, Zolldann D, Stanzel S, Lütticken R. Distribution of multi-resistant gram-negative versus gram-positive bacteria in the hospital inanimate environment. J Hosp Infect 2004;56(3):191-7.

12. Qureshi WK, Palayekar V, Dayan E, James P. Mack JP, Rojtman A. Combating the antibiotic resistance threat. Int J Pharm Pharm Sci 2015;7(2):68-72.

13. Mangram AJ, Horan TC, Pearson ML, Silver LC, Jarvis WR. Guideline for prevention of surgical site infection, 1999. Am J Infect Control 1999;27:97-134.

14. Chaari A, Mnif B, Bahloul M, Mahjoubi F, Chtara K, Turki O, et al. Acinetobacter baumannii ventilator-associated pneumonia: Epidemiology, clinical characteristics, and prognosis factors. Int $\mathrm{J}$ Infect Dis 2013;17(12):e1225-8.

15. Wadhwa R, Sharma Y, Upadhyay RP, Bala K. Nosocomial infection by non-fermenting gram negative bacilli in tertiary care hospital: Screening and cure. Int J Pharm Pharm Sci 2016;8(3):274-7. 